Lawanga, P.W.A.H. and Sandanayake, Y.G., 2021. Lean design management practices associated with stakeholder management during pre-construction stage in Sri Lanka. In: Sandanayake, Y.G., Gunatilake, S. and Waidyasekara, K.G.A.S. (eds). Proceedings of the $9^{\text {th }}$ World Construction Symposium, 9-10 July 2021, Sri Lanka. [Online]. pp. 392-402. DOI: https://doi.org/10.31705/WCS.2021.34. Available from: https://ciobwcs.com/papers/

\title{
LEAN DESIGN MANAGEMENT PRACTICES ASSOCIATED WITH STAKEHOLDER MANAGEMENT DURING PRE- CONSTRUCTION STAGE IN SRI LANKA
}

\author{
P.W.A.H. Lawanga ${ }^{1}$ and Y.G. Sandanayake ${ }^{2}$
}

\begin{abstract}
Lean Design Management (LDM) is a concept, which ensures efficiency and effectiveness of the design stage of a construction project to reduce uncertainty and improve the quality of the final product. Stakeholder Management (SM) is an effective approach for coordinating and managing stakeholders who involve with a construction project to ensure better relationships and reduce the complexity of the project. The integration of LDM and SM concepts together into the pre-construction phase provides a positive impact on the project performance. This paper aims to investigate the lean design management practices associated with stakeholder management in the pre-construction phase of construction projects in Sri Lanka. The research has used mixed method research approach to achieve the aforementioned aim. The research concluded that twenty-nine lean design management practices and eight stakeholder management practices can be integrated into the pre-construction phase in Sri Lanka. The findings further revealed that waste reduction, product performance enhancement, and functionality enhancement can be achieved by integrating LDM and SM practices together into the pre-construction phase in Sri Lanka.
\end{abstract}

Keywords: Construction projects; Lean Design Management (LDM); Pre-construction phase; Sri Lanka; Stakeholder Management (SM).

\section{INTRODUCTION}

The construction industry plays a major role in the social and economic development of a country (Ofori, 2015). Therefore, effective and efficient management of the pre-construction stage is an important task for the final output (Reifi and Emmitt, 2013). According to Dolage and Perera (2009), management of the pre-construction phase plays an important role in construction life cycle depend on challenges that occur during this phase. These challenges and issues that occur in the pre-construction stage affect the construction life cycle and efficiency and quality of the final output (Daluwatte and Ranasinghe, 2018). Lean Design Management (LDM) is a strategic management tool that the philosophy derived from the lean construction concept to communicate overcomes of the disorderly design process in construction (Mota $e t$ al., 2019). According to Bourne and Walker (2005), Stakeholder Management (SM) is considered as an effective approach for coordinating and managing stakeholders to keep a good relationship and reduce the complexity of the project.

The effective management of stakeholders on a project is an important area in the project management process (Jergeas et al., 2000). In the global context, LDM and lean practices have

\footnotetext{
${ }^{1}$ Department of Building Economics, University of Moratuwa, Sri Lanka, hlawanga@ hotmail.com

${ }^{2}$ Department of Building Economics, University of Moratuwa, Sri Lanka, ysandanayake@uom.lk
} 
been evaluated through different studies. However, the relationship between SM and LDM in pre-construction phase has been studied only in few researches. Herrera et al. (2019) researched to evaluate the relationship between LDM principles and SM practices based on opinions of international experts during the pre-construction stage in Chile, Colombia, and Span. Moreover, that study was limited to investigate the relationships between Koskela's lean construction principles and SM practices during the pre-construction stage. However, there is a gap still not filled related to stakeholder management practices and LDM practices in the preconstruction phase when it comes to the Sri Lankan context. Therefore, the purpose of this paper is to investigate the twenty- nine lean design management practices associated with eight stakeholder management practices that can be used during the pre-construction phase of construction projects in Sri Lanka.

\subsection{Lean Design Management Practices (LDMP)}

Lean design management simply describes the way of communicating how to overcome the disorderly design process in lean construction (Herrera et al., 2019). Uusitalo et al. (2017) described that LDM concept is based on the lean construction concept, which focuses on two main values called minimising waste, and creating values. Furthermore, Kumar and Abuthakeer (2019) found that new practices, tools, and techniques are implementing to minimise the overcomes of the disorderly design process. Babalola et al. (2019) have elaborated lean practices that are applied in the present industry and categorised those practices into four basic categories based on their application in the industry.

Table 1 presents the lean design management tools and practices under four categories.

Table 1: Categories of lean design management tool and techniques

\begin{tabular}{|c|c|}
\hline Categories & Lean Design Management Practices and Tools \\
\hline Design and Engineering Practices & $\begin{array}{l}\text { - Virtual Design Construction (VDC): (LDMP1) } \\
\text { - Design Structure Matrix (DSM): (LDMP2) } \\
\text { - Prefabrication and Modularisation: (LDMP3) } \\
\text { - Detailed Briefing: (LDMP4) } \\
\text { - Design Workshop or Big Room workshop: (LDMP5) } \\
\text { - Integrated Project Delivery (IPD): (LDMP6) } \\
\text { - Target Value Design (TVD): (LDMP7) } \\
\text { - Standardisation: (LDMP8) } \\
\end{array}$ \\
\hline Planning and Control Practices & $\begin{array}{l}\text { - Last Planner system (LPS): (LDMP9) } \\
\text { - Work Structuring and Scheduling: (LDMP10) } \\
\text { - Benchmarking: (LDMP11) } \\
\text { - Location- Based Management (LBM): (LDMP12) } \\
\text { - Six Sigma: (LDMP13) } \\
\text { - Value Based Management/Value Streaming Mapping } \\
\text { (VBM/VSM): (LDMP14) } \\
\text { - Pull Scheduling/Planning: (LDMP15) } \\
\text { - Reduce time: (LDMP16) } \\
\text { - Simplify Steps: (LDMP17) } \\
\text { - Increasing Flexibility: (LDMP18) } \\
\text { - Focus on the Whole Process: (LDMP19) } \\
\text { - Increase Transparency (LDMP20) } \\
\text { - First run Study: (LDMP29) }\end{array}$ \\
\hline
\end{tabular}




\begin{tabular}{ll}
\hline \multicolumn{1}{c}{ Categories } & \multicolumn{1}{c}{ Lean Design Management Practices and Tools } \\
\hline & - Visualization tools/Management (VM): (LDMP21) \\
& - Teamwork and partnering: (LDMP22) \\
Construction and Site & - Total Quality Management (TQM): (LDMP23) \\
Management Practices & - Kaizen: (LDMP24) \\
& - Conference management (CM): (LDMP25) \\
& - Kanban System: (LDMP26) \\
\hline \multirow{3}{*}{ Health and Safety Management } & Health and Safety Improvement Management: \\
Practices & (LDMP27) \\
& Plan of Conditions and Work Environment or \\
& Environmental Management System: (LDMP28) \\
\hline
\end{tabular}

Source: (Babalola et al., 2019; Herrera et al., 2019)

As elaborated in Table 1, LDM practices can be categorised based on areas of their possible implementation in the design, planning, and construction projects (Babalola et al., 2019). Moreover, each LDM practices is used as strategic solutions to minimise wastage in different situations during the pre-construction stage. However, the identified twenty-nine (29) LDM practices were assessed whether those practices are applying when it comes to Sri Lankan construction projects during the pre-constriction stage.

\subsection{STAKeHOLDER MANAGEMENT (SM)}

As per Bourne and Walker (2005), stakeholder management is considered an effective approach for coordinating and managing stakeholders to keep a good relationship and reduce the complexity of the project. However, the involvement of stakeholders in the pre-construction stage is considered an important management practice that can provide better management through the whole process (Aapaoja et al., 2013). Molwus et al. (2017) have stated that the SM concept is a critical element for the management of construction projects. The review on stakeholder management practices can be summarised under Table 2 .

Table 2: Stakeholder management practices during pre-construction stage

\begin{tabular}{ll}
\hline \multicolumn{1}{c}{ Stakeholder Management Practices } & \multicolumn{1}{c}{ Sources } \\
\hline $\begin{array}{l}\text { Specialist designers are involved during the early stages } \\
\text { of the project. (SM1) }\end{array}$ & $\begin{array}{l}\text { (Knotten } \text { et al., 2016; Reifi and } \\
\text { Emmitt, 2013) }\end{array}$ \\
$\begin{array}{l}\text { The identification of requirements of the stakeholders: } \\
\text { Identified special requirements, technical specifications. } \\
\text { (SM2) }\end{array}$ & $\begin{array}{l}\text { (Reifi and Emmitt, 2013; Herrera } \text { et al., } \\
\text { Builders are involved during the early stage of the } \\
\text { project. (SM3) }\end{array}$ \\
$\begin{array}{l}\text { The participation of the employer during the early stage } \\
\text { and their support to the other stakeholders. (SM4) }\end{array}$ & (Knotten et al., 2016) \\
$\begin{array}{l}\text { The participant of the client during decision making and } \\
\text { resolution of problems. (SM5) }\end{array}$ & (Salgin et al., 2016) \\
$\begin{array}{l}\text { The involvement of the consultant party during legal and } \\
\text { promissory conditions. (SM6) }\end{array}$ & (Chinyio and Olomolaiye, 2010) \\
$\begin{array}{l}\text { The involvement of a consultant party during manage } \\
\text { external and internal stakeholders who deal with }\end{array}$ & (Franco and Picchi, 2016) \\
$\begin{array}{l}\text { Employer. (SM7) } \\
\begin{array}{l}\text { The design of the product and the construction process } \\
\text { are carried out instantaneously. (SM8) }\end{array}\end{array}$ \\
\hline
\end{tabular}


As stated by the above SM practices, each SM practice is mainly applied in the construction industry to enhance the efficiency of stakeholder management procedure during the preconstruction stage. However, above eight (08) SM practices were assessed whether those practices are applying when it comes to Sri Lankan construction projects during the preconstriction stage.

\subsection{IMPORTANCE OF THE IMPLEMENTATION OF LDM AND SM INTO THE PRE- CONSTRUCTION STAgE}

LDM is an important management strategy that increases the value of the final output of a construction project (Reifi and Emmitt, 2013). Improving the quality and the value of the project are other key benefits that can be gain through the LDM implementation (Mota et al., 2019). Furthermore, LDM is focusing on two main values called minimising waste and creating value to enhance the project performance during the pre-construction stage (Babalola et al., 2019). Moreover, LDM concept is being applied as a management strategy in construction projects to enhance project performance (Herera et al., 2019).

SM is another important activity that is being used to gain a mutual understanding of the objectives and expectations of all parties (Rajabul et al, 2015), Besides, delivering the success of the project is the main objective of SM in construction projects. Walt (2020) has identified SM as an important strategy because it addresses the whole project life cycle to create effective project relationships. Further, SM involves with developing the management planning, engaging and communicating with difficulties of a construction project to ensure the stakeholder expectation and project enhance performance (Walt, 2020).

When both management strategies are considered, only a few researchers discuss about the importance of implementation of both strategies. However, Herrera et al. (2019), have identified the importance of the implementation of LDM and SM during the pre-construction through their study. Increasing the final value of the project, reducing the cycle time, reducing the process variability, and increasing the efficiency of the process are the key importance that can achieve from the implementation of the LDM and SM together into the pre-construction stage (Herrera et al., 2019). Moreover, Herrera et al. (2019) found that LDM and SM are the key areas that affect project performance.

\section{RESEARCH METHODOLOGY}

The research was initiated with a comprehensive literature review which was included a broad perspective of LDM and SM concepts and their applications during the pre- construction stage. This research used a mixed-method approach as it consists of quantitative and qualitative research approaches. However, data collection was done through semi semi-structured interviews to investigate the level of awareness and importance of the LDMP and SMP in the Sri Lankan construction sector and appraise the relationship between LDMP and SMP in preconstruction phase of construction projects in Sri Lanka. The outcomes were evaluated by comparing with findings and validation through the literature survey to identify the suitability of the LDM practices and SM practices for the pre-construction stage of the Sri Lankan construction. Therefore, the content analysis was selected as the qualitative analysis method to investigate the current lean and stakeholder management practices at pre-construction stage. Finally, quantitative analysis was utilised for the identification of the relationship between lean construction principles and stakeholder management practices at pre-construction stage of the Sri Lankan construction industry. 


\section{RESEARCH FINDINGS}

The semi-structured interviews were conducted with thirty-five (35) professionals who have experience in the pre-construction stage at Sri Lankan construction projects. Respondents were selected using snowball sampling technique. Tables 3 and 4 provide the summary of respondents contacted in data collection.

Table 3: Summary of respondent's profile

\begin{tabular}{lccccc}
\hline & $\begin{array}{c}\text { Civil } \\
\text { Engineers }\end{array}$ & Architects & $\begin{array}{c}\text { Mechanical } \\
\text { Engineers }\end{array}$ & $\begin{array}{c}\text { Quantity } \\
\text { Surveyors }\end{array}$ & $\begin{array}{c}\text { Total Number of } \\
\text { Respondents }\end{array}$ \\
\hline $\begin{array}{l}\text { Proportions of } \\
\text { respondents }\end{array}$ & 19 & 8 & 3 & 5 & 35 \\
$(\%)$ & $(54 \%)$ & $(23 \%)$ & $(9 \%)$ & $(14 \%)$ & $(100 \%)$ \\
\hline
\end{tabular}

Table 4: Working experience of the respondents

\begin{tabular}{|c|c|c|c|c|c|c|c|}
\hline & 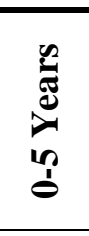 & 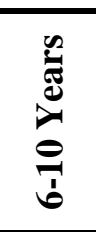 & 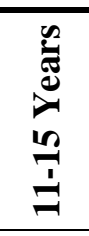 & 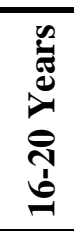 & 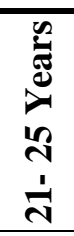 & 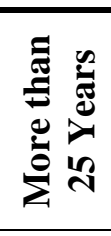 & 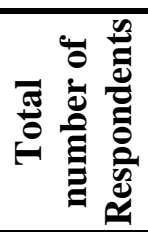 \\
\hline $\begin{array}{l}\text { Proportions of } \\
\text { respondents }\end{array}$ & 7 & 14 & 6 & 2 & 1 & 4 & 35 \\
\hline$(\%)$ & $21 \%$ & $41 \%$ & $18 \%$ & $6 \%$ & $3 \%$ & $12 \%$ & 100 \\
\hline
\end{tabular}

\subsection{RESEARCH FINDINGS}

\subsubsection{Awareness of LDM and SM Concepts at the Pre-construction Stage}

Table 5 summarised the result of analytical data regarding the awareness of LDM concept and SM concept by the professional who involved in the construction industry and its implementation at the pre-construction stage in the Sri Lankan construction sector.

Table 5: Awareness of lean design management concept and stakeholder management concept

\begin{tabular}{lcc}
\hline & LDM Concept & SM Concept \\
\hline Number of respondents having awareness & $32(91 \%)$ & $34(97 \%)$ \\
Number of respondents with lack of awareness & $3(9 \%)$ & $1(3 \%)$ \\
Total number of respondents & $\mathbf{3 5 ( 1 0 0 \% )}$ & $\mathbf{3 5 ( 1 0 0 \% )}$ \\
\hline
\end{tabular}

As per the analytical data, 91\% of respondents aware of LDM concept. However, 9\% of respondents have some understanding despite a lack of experience regarding LDM concept. Furthermore, $91 \%$ of respondents aware of the SM concept. However, $3 \%$ of respondents have some understanding despite lack of experience regarding SM concept.

\subsubsection{The Relationship between SM Practices and LDM Practices}

To investigate the SM practices, their relationship with the twenty-nine (29) LDMP were investigated through semi-structured interviews. The opinion of 35 respondents was used to appraise whether the SM and LDM practices have a strong (complete) relationship, a partial relationship or relationship was non-existent.

The descriptive analysis was used as the analysis technique for this study. The mean value of the 35 respondent's answers was used to assess the relationships between these two variables. 


$$
\text { Mean Value }=\Sigma x i \div n
$$

According to the results, each relationship was assessed through the rules given in Table 6.

Table 6: Nature of the relationships

\begin{tabular}{ll}
\hline \multicolumn{1}{c}{ Mean Value } & \multicolumn{1}{c}{ Nature of the Relationship } \\
\hline Mean Value $=0-0.5$ & Non-existing relationship \\
Mean Value $=0.50-1.50$ & Partial relationship \\
Mean Value $=1.50-2.00$ & Strong (Complete) relationship \\
\hline
\end{tabular}

There were 232 possible SM and LDMP relationships were assessed under this study. When these 232 possible were assessed during interviews, 55 possible had strong (Complete) relationships, 145 had partial relationships, and other 32 did not have any relationships. The number of total connections between SMP and LDMP were 200 (including both partial and strong relationships), which accounted for $86.21 \%$ of all potential relationships. In addition to that, when considering all potential relationships, $27.50 \%$ were complete relationships, and $72.50 \%$ were partial relationship. Figure 1 shows the number of LDMP that each of the SMP contributed to relationships.

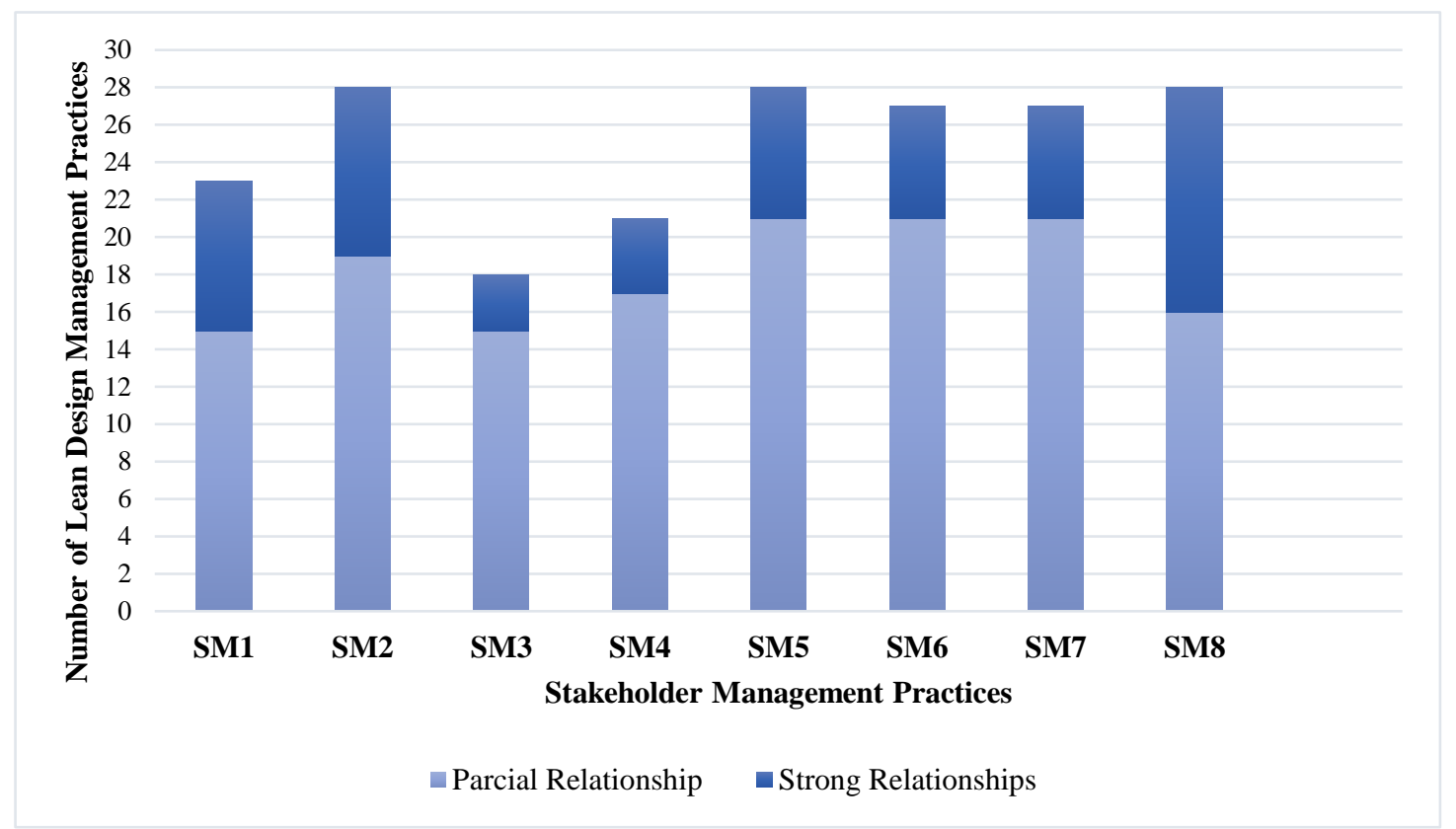

Figure 1: The number of LDMP that each of the SM practices contributed to relationships

On average SM practices were subjected to as a minimum 18 LDMP, and a maximum of 28 out of 29 LDMP that were assessed during the data collection procedure.

\subsubsection{Complete Relationship between SM and LDM Practices}

The judgement of 35 respondents regarding 232 possibles between these two variables was used to validate the relationship between LDM practices and SM practices. However, the mean value of those answers was used to establish the relationship between LDM and SM practices. As per the result of the analysis, there was a complete (strong) relationship for the 55 possible among 232 of total possible that had been assessed during the study. The association of 55 complete relationships was separated into eight SMP and it could be presented as the node diagram. Figure 2 shows the strong relationships between SMP and LDMP compactly as a node diagram. 


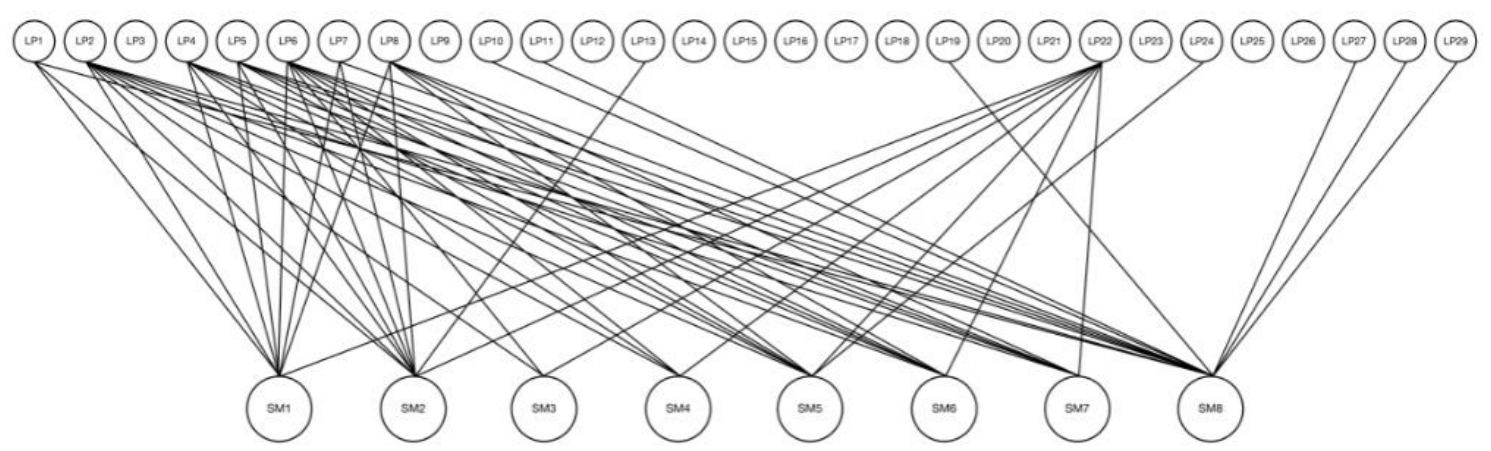

Figure 2: Strong (complete) relationships between SM practice and LDMP

On average, the involvement of builders during the early stage of the project (SM3) is the SMP that shows the least complete correlation with LDMP during the pre-construction stage. It has built up complete relationships with three LDMP namely Design Structure Matrix, Integrated Project Delivery, and Teamwork and Partnering. According to the study, the design of the product and the construction process are carried out instantaneously (SM8) is the SMP that has shown a complete relationship with more LDMP when comparing to other SM practice variables. SM8 had associated with twelve LDMP during the pre-constructions stage according to the node diagram. Virtual Design Construction, Design Structure Matrix, Design Workshop or Big Room workshop, Integrated Project Delivery, Target Value Design, Standardisation, Work Structuring and Scheduling, Benchmarking, Focus on the Whole Process, Health and Safety Improvement Management, Plan of Conditions and Work Environment or Environmental Management System, and First run Study were associated LDMP with SM8. When considering other SMP, SM6 and SM7 built up strong relationships with six same LDMP. In addition to that SM1, SM2, SM4, and SM5 build up complete relationships with eight, nine, four and seven LDMP.

\subsubsection{Partial Relationship between SM and LDM Practices}

145 partial relationships shown in the node diagram had been briefly described here based on each SMP that are applied pre-construction stage in Sri Lankan construction projects.

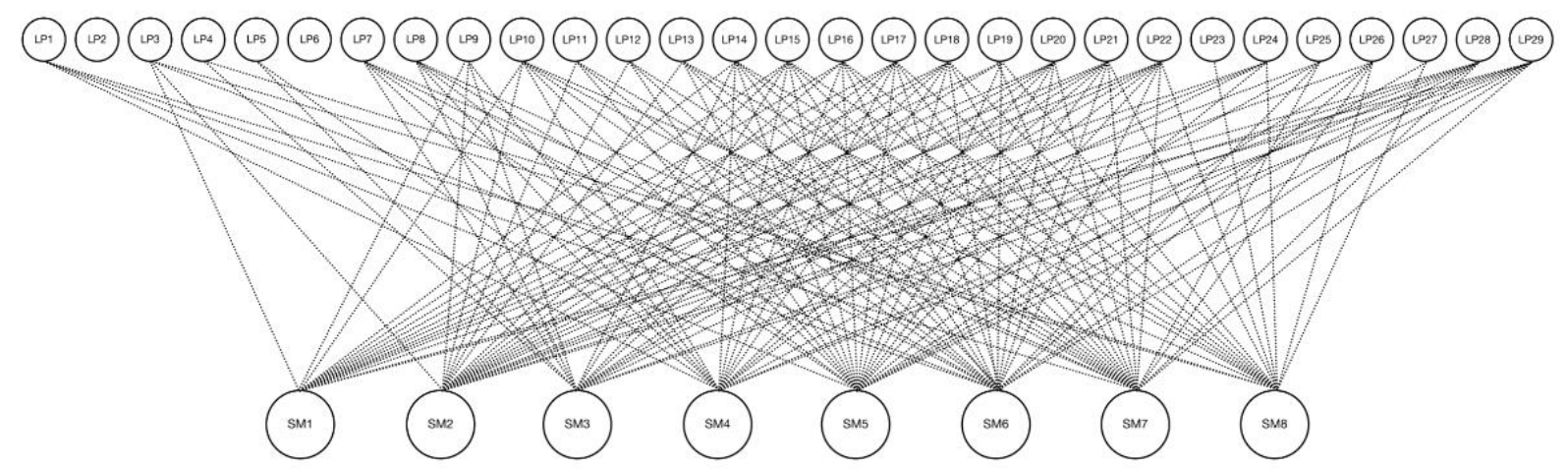

Figure 3: Partial relationship between LDMP and SMP

According to Figure 3, SM5, SM6, and SM7 are the SM practices that have shown partial relationship between more LDMP comparing other SM variables. These three variables are associated with 21 LDMP during the pre-construction stage. On average, SM1 and SM3 are the SM practices that shows the least partial correlation with LDMP during the pre-construction stage. These variables built up partial relationships with 15 LDMP. Furthermore, SM2, SM4 and SM8 build-up partial relationships consecutively 19, 17 and 16 LDMP. 


\subsubsection{Possibility of Implementation of LDMP into SM Practices at the Pre-construction Stage}

The possibility of implementation of each LDMP into SM practices at the pre-construction stage could be assessed by using the outcomes from the descriptive analysis. Further, the possibility of implementation of LDMP could be assessed through two categories namely LDMP, which has a strong capability of implementation and LDMP, which has a partial capability with implementation. The probability was calculated considering both the partial and complete relationship that SMP built up with LDMP.

$$
\text { P-value }=\frac{\text { Number of relationship associated with each } L P}{\text { Total relationship possible }}
$$

Table 7 has comprised the probability of integrating LDMP into SM practices strongly and partially during the pre-construction stage.

Table 7: Probability of integrating LDMP into SM practices during the pre-construction stage

\begin{tabular}{|c|c|c|}
\hline Lean Design Management Practice & $\begin{array}{c}\text { Probability of } \\
\text { implementation } \\
\text { completely }\end{array}$ & $\begin{array}{c}\text { Probability of } \\
\text { implementation } \\
\text { partially }\end{array}$ \\
\hline Virtual Design Construction (VDC) & 0.015 & 0.020 \\
\hline Design Structure Matrix (DSM) & 0.040 & \\
\hline Prefabrication and Modularisation & & 0.025 \\
\hline Detailed Briefing & 0.030 & 0.010 \\
\hline Design Workshop or Big Room workshop & 0.030 & 0.010 \\
\hline Integrated Project Delivery (IPD)) & 0.040 & \\
\hline Target Value Design (TVD) & 0.015 & 0.025 \\
\hline Standardisation & 0.030 & 0.010 \\
\hline Last Planner System (LPS) & & 0.035 \\
\hline Work Structuring and Scheduling & 0.005 & 0.020 \\
\hline Benchmarking & 0.005 & 0.020 \\
\hline Location-Based Management (LBM) & & 0.025 \\
\hline Six Sigma & 0.005 & 0.035 \\
\hline $\begin{array}{l}\text { Value-Based Management/Value Streaming } \\
\text { Mapping (VBM/VSM) }\end{array}$ & & 0.040 \\
\hline Pull Scheduling/Planning & & 0.035 \\
\hline Reduce time & & 0.040 \\
\hline Simplify Steps & & 0.040 \\
\hline Increasing Flexibility & & 0.030 \\
\hline Focus on the Whole Process & 0.005 & 0.035 \\
\hline Increase Transparency & & 0.040 \\
\hline Visualization tools/Management (VM) & & 0.040 \\
\hline Teamwork and partnering & 0.035 & 0.005 \\
\hline Total Quality Management (TQM) & & 0.025 \\
\hline Kaizen & 0.005 & 0.020 \\
\hline Conference management (CM) & & 0.025 \\
\hline
\end{tabular}




\begin{tabular}{lcc}
\hline \multicolumn{1}{c}{ Lean Design Management Practice } & $\begin{array}{c}\text { Probability of } \\
\text { implementation } \\
\text { completely }\end{array}$ & $\begin{array}{c}\text { Probability of } \\
\text { implementation } \\
\text { partially }\end{array}$ \\
\hline Kanban System & 0.005 & 0.010 \\
Health and Safety Improvement Management & 0.005 & 0.035 \\
Plan of Conditions and Work Environment or & & 0.035 \\
Environmental Management System & 0.005 & 0.035 \\
First run Study & & \\
\hline
\end{tabular}

According to the probability values that have been presented in Table 7, majority of LDMP have more possibility to associate partial implementation with SM practices during the preconstruction stage in Sri Lankan construction projects rather than complete implementation. When the 29 LDMP were considered used for the research, there were 17 LDMP, which have the considerable capability of the partial or complete implementation with SM practices during the pre-construction stage at Sri Lankan construction projects. However, there is a considerable possibility for the implementation of LDMP with SM practices during the pre-construction stage.

\subsubsection{Importance of Implementing LDMP with SM Practices during the Pre- construction Stage}

Increasing the value and the quality of the design minimising errors, reducing unnecessary cost and time that is allocated to design procedure, providing flexibility for the design based on the requirement, increasing project coordination, identification of construction difficulties, and minimising them during pre-construction stage could be identified as the key benefits of integrating LDMP into SM. On the other hand, reducing the process variability, increasing the final product value through systematic consideration of client's requirement, reducing cycle time, reducing the non-value activities, increasing the process transparency, and continuous improvement process were identified as the other benefits that can be gained from the integration of LDMP into SMP during the pre-construction stage.

The respondents who have more experience with the construction industry emphasised that even if LDMP and SM are currently existing as management practices in Sri Lankan construction projects, the professionals do not have considerable knowledge on the implementation of those practices with construction projects. On the other hand, construction professionals reluctant to adopt the new concept that is coming to the Sri Lankan construction sector. Therefore, the professionals have a lack of experience and knowledge regarding new concepts that can provide considerable value to the construction sector. In summary, the majority of construction professionals have applied LDMP and SM practices during the preconstruction stage without knowing them as LDMP and SM practices due to a lack of theoretical knowledge that the professionals have. Therefore, the majority of the respondents described the importance of guiding professionals who involve with a construction project to enhance both theoretical and practical knowledge. However, according to the opinion of the respondents, it will be required to provide training regarding important management practices such as LDM and SM practices that have considerable capability to enhance the effectiveness and efficiency of the pre-construction process in the Sri Lankan construction sector. 


\section{CONCLUSIONS}

In this study, 29 lean design management practices and eight (08) stakeholder management practices were identified under literature synthesis. These practices were assessed during the data collection procedure for achieving the aim of the research. However, due to time constraints, the scope of the research was limited to appraise the relationship between LDM practices and SM practices at pre-construction stage.

As per the viewpoint of experts, there is a $70 \%$ possibility of implementation of LDMP during the pre-construction stage and an $82 \%$ possibility of implementation of SM practices during the pre-construction stage when it comes to the Sri Lankan context. The implementation of LDMP during the pre-construction stage ensures the efficiency and effectiveness of a construction project by minimising waste and increasing the quality of a project. On the other hand, SMP provide a lower probability of developing the poor design through the better coordination of the stakeholders. Moreover, when considering the relationships between LDM and SM practices, there was a $61.64 \%$ possibility for integrating both variables during the preconstruction stage. These relationships have build-up under two categories called strong relationships and partial relationships. According to the results from the analysis, LDMP had a considerable possibility to create a partial relationship with SM practices rather than strong relationships.

When the Sri Lankan context is considered, numerous benefits can be gain through this implementation. Increasing value and the quality of the design, reducing unnecessary cost and time that is allocated to design procedure, providing flexibility for the design based on the requirement, and increasing project coordination were identified as main benefits of the implementation. Conversely, the implementation can influence the efficiency and effectiveness of the final output. However, though there is progressive earnest for implementing LDM into the pre-construction stage, the majority of construction professionals have a lack of awareness and poor earnestness with the implementation of LDM into the pre-construction stage. Therefore, the experts have focused on preparing the strategical process for implementing LDM into the pre-construction stage to increase productivity and minimise the complexity of the process in Sri Lankan construction projects.

\section{REFERENCES}

Aapaoja, A., Haapasalo, H., and Soderstorm, P., 2013. Early stakeholder involvement in the project definition phase: Case renovation. ISRN Industrial Engineering, 2013, pp. 1-14.

Babalola, O., Ibem, E.O., and Ezema, I.C., 2019. Implementation of lean practices in the construction industry: A systematic review. Building and Environment, 148, pp. 34- 43.

Bourne, L., and Walker, D.H., 2005. Visualising and mapping stakeholder influence. Management Decision, 43(5), pp. 649-666.

Chinyio, E., and Olomolaiye, P. (Eds.)., 2010. Construction stakeholder management. United Kingdom: Blackwell Publishing Ltd.

Daluwatte, L. and Ranasinghe, M., 2018. Effects of inputs from the preconstruction activities on the design phase of construction projects. Engineer: Journal of the Institution of Engineers, Sri Lanka, 51(2), pp. 31-40.

Dolage, D.A.R. and Perera, P.W.S.D., 2009. Delays in the pre-construction phase of state sector building projects. Engineer: Journal of the Institution of Engineers, Sri Lanka, 42(3), pp. 22-30.

Franco, J.V., and Picchi, F.A., 2016. Lean design building projects: Guiding principles and exploratory collection of good practices. $24^{\text {th }}$ Annual Conference of the International Groups for Lean Construction. [Online] 4, pp. 113-122. Boston, USA: IGLC. Available from: https://iglcstorage.blob.core.windows.net/papers/attachment5d954305-e6f3-4c5b-9ee7-4a03eafd2d70.pdf.

Herrera, R., Mourgues, C., Alarcon, L.F. and Pellicer, E., 2019. An assessment of lean design management practices in construction projects. Sustainability, 12(1), pp. 1-19. 
Jergeas, D. F., Williamson, E., Skulmoski, G. J. and Thomas, D. L. 2000. Stakeholder management on construction projects. AACE International Transactions, 12, pp. 12.1-12.6.

Knotten, V., Svalestunen, F., Laedre, O. and Hansen, G.K., 2016. Improving design management with mutual assessment. 24th Annual Conference of the International Group for Lean Construction. [Online] 4, pp. 173182. Boston, USA. Available from:

<https://www.researchgate.net/publication/305747580_IMPROVING_DESIGN_MANAGEMENT_WITH_ MUTUAL_ASSESSMENT//www.researchgate.net/publication/305747580.> [Accessed 4 June 2020].

Kumar, B.S. and Abuthakeer, S., 2012. Implementation of lean tools and techniques in automation industry. Journal of Applied Science, 12(10), pp. 1032-1037.

Molwus, J.J., Erdogan, B. and Ogulana, S., 2017. Using Structural Equation Modelling (SEM) to Understand the Relationships among Critical Success Factors (CSFs) for Stakeholder Management in Construction. Engineering, Construction and Architectural Management, 24(3), pp. 426-450.

Mota, B., Biotto, C., Choudhury, A., Abley, S. and Kagioglou, M., 2019, Lean design management in a major infrastructure project in UK, In: Proceedings of $27^{\text {th }}$ Annual Conference of the International Group for Lean Construction (IGLC). Dublin, Ireland, 3-5 Jul 2019. pp 37-48.

Ofori, G., 2015. Nature of the construction industry, its needs and its development: A review of four decades of research. Construction in Developing Countries, 20(2), pp. 115-135.

Rajabul, M., Marthandan, G., Fadzilah, W. and Yusoff, W.F., 2015. Managing for stakeholders: The role of stakeholder-based management in project success. Asian Social Science, 11(3), pp. 111-124.

Reifi, M. and Emmitt, S., 2013. Perceptions of lean design management. Architectural Engineering and Design Management, 9(3), pp. 195 - 208.

Salgin, B., Arroyo, P. and Ballarad, G., 2016. Exploring the relationship between lean design methods and C\&D waste reduction: Three case studies of hospital projects in California. Revista Ingenieria Construction, 31(3), 191-200.

Uusitalo, P., Olivieri, H., Seppänen, O., Pikas, E. and Peltokorpi, A., 2017. Review of lean design management: processes, methods and technologies. In Proceedings of the $25^{\text {th }}$ annual conference of the international group for lean construction, July 2017, Heraklion, Greece, pp. 9-12.

Walt, D., 2020. Importance of project stakeholder management. [ebook] Owner Team Consultation (OTC), pp.19. [Online] Available from: <https://www.ownerteamconsult.com/wp-content/uploads/2020/07/InsightArticle-075-Importance-of-Stakeholder-Management.pdf> [Accessed 8 May 2020]. 